\title{
Clinical and Sociodemographic Risk Factors for Tuberculosis in Human Immunodeficiency Virus Infected Patients
}

\author{
${ }^{1}$ Paz-Ayar Nibardo, ${ }^{1}$ Jose Antonio Mata-Marin, \\ ${ }^{1}$ Jesus Gaytan-Martinez, ${ }^{2}$ Gloria Huerta-Garcia and ${ }^{1}$ Benjamin Acosta-Cazares \\ ${ }^{1}$ Department of Infectious Diseases, Hospital de Infectologia, "La Raza” National Medical Center, IMSS, Mexico \\ ${ }^{2}$ Department of Pediatric Infectious Diseases, "Siglo XXI" National Medical Center, IMSS, Mexico
}

Received 2013-08-01; Revised 2013-11-12; Accepted 2013-11-30

\begin{abstract}
To identify clinical and sociodemographic factors associated with the risk of tuberculosis in HIV-infected patients. A case-control study in a cohort of hiv-infected patients. Cases: patients coinfected with HIV and pulmonary or extrapulmonary tuberculosis. Controls: no clinical tuberculosis and PPD negative, matched for age and sex. Primary data were obtained from medical records and personal interviews. We identified 47 cases and 94 controls. The main risk factors identified were: underweight (malnutrition) $(\mathrm{BMI} \leq 18.49)$, abscence of antiretroviral therapy, CD $4+$ cells count $\leq 199$ cells $/ \mathrm{mm}^{3}$, RNA HIV-1 viral load $\geq 100,000$ copies/mL. Tuberculosis is associated to multiple risk factors in HIV infected patients, clinical factors are more important that sociodemographic ones. CD4+ cells count $<200$ cells $/ \mu \mathrm{L}$, malnutrition IMC $<18.9$ and RNA HIV-1 viral load $>100,000$ copies $/ \mathrm{mL}$ are associated with tuberculosis in HIV infected patients.
\end{abstract}

Keywords: HIV, Tuberculosis Risk Factors, Clinical, Sociodemographic

\section{INTRODUCTION}

Tuberculosis (TB) caused by Mycobacterium tuberculosis, is considered one of the most common opportunistic infections in individuals infected with Human Immunodeficiency Virus (HIV) and is the leading cause of death which is estimated at $13 \%$ of individuals with Acquired Immunodeficiency Syndrome (AIDS) worldwide (Blanc et al., 2011; Alvarez-Uria et al., 2013; Kyeyune et al., 2010).

Global estimates suggest that one in three people living with HIV are infected with TB and 40-60\% of these will develop active $\mathrm{Tb}$ (Kaplan et al., 2009). The risk of developing active TB in HIV patients is 5-15\% per year, due to reactivation of latent infection which generally depends of the inmunocompromised degree (Fox et al., 2013).

Mexico recorded a prevalence of HIV infection of $0.3 \%$ in the population aged 15-49 years old, ranked third in the Americas, with an estimated incidence of 267 per 100,000 habitants (Bautista-Arredondo et al., 2013;
De Luca et al., 2010). Coinfection HIV/Tb varies between 4 and $9 \%$ in the different Mexico states (Zenteno-Cuevas et al., 2011). The mortality rate associated with HIV reported by the Mexican Social Security Institute (IMSS) in 2009 was 3.35 per 100,000 patients (Vazquez-Martinez et al., 2011).

Factors traditionally associated with acquisition of infection, disease development and mortality from $M$. Tuberculosis are complex. Factors most frequently found are: poverty, malnutrition, overcrowding, lack of ventilation and lighting in homes, alcohol, smoking and other drugs, pregnancy, corticosteroids use, lack of access to merg services and presence of other associated conditions such as diabetes (Gomes et al., 2013). Household contacts with TB infected merg also a known and risk factor for development tuberculosis, especially in endemic areas (Fox et al., 2013). HIV infection has joined the long list of risk factors and confers increased risk for active $\mathrm{Tb}$ (Gomes et al., 2013).

HIV has facilitated the re-emergence of TB in over three decades and has also helped to change the clinical

Corresponding Author: Paz-Ayar Nibardo, Department of Infectious Diseases, Hospital de Infectologia, "La Raza" National Medical Center, IMSS, Mexico 
and epidemiological spectrum of it, leading to the mergente of new risk factors, higher rates of relapse and mortality as well as a high percentage of extrapulmonary clinical forms (Sterling et al., 2010).

The aim of this study was to identify demographic and clinical factors that are associated with risk of tuberculosis in HIV-infected patients treated at the Hospital de Infectologia "La Raza" National Medical Center, IMSS.

\section{MATERIALS AND METHODS}

A case-control study was conducted from March 1 to June 30, 2012, in a cohort of 700 patients infected with HIV, diagnosed by ELISA and confirmed by Western blot, treated at the Hospital de Infectologia "La Raza" National Medical Center, Mexico City. We included 47 patients aged $\geq 16$ years, diagnosed with pulmonary or extrapulmonary TB, they were tested by smear, culture, histopathology or PCR and in whom the symptoms, physical signs, diagnostic aids and therapeutic response suggested the existence of $\mathrm{Tb}$ with initial negative bacteriological results. 94 controls were recruited, two per case, matched for age and sex ( \pm 5 years) with no clinical evidence, microbiological or molecular of $\mathrm{Tb}$ and tuberculin skin test (PPD) negative. PPD test was performed using $0.1 \mathrm{~mL}$ of purified protein derivative of tuberculin of $2.0 \mathrm{IU} \mathrm{mL}$, given intradermally on the forearm by the Mantoux method and measured $72 \mathrm{~h}$ after application. The positive cutoff for this test was considered as induration $\geq 5 \mathrm{~mm}$. We excluded patients who could not complete the questionnaire and/or had a history of non-tuberculous mycobacterial infection. Among the potential controls 3 patients were removed, for having tested positive to PPD.

Demographic, social, economic, illicit drug use, alcohol and smoking were obtained through a questionnaire administered to the patient during a personal interview, in that moment, PPD application was made, for the presence of latent $\mathrm{TB}$, to controls. Sociodemographic factors were composed of the following variables: Sex, age, occupation, education level, socioeconomic status (SES AMAI index 10×6), marital status and county of birth, place of residence and stay in high-risk sites. High-risk demographic entity of $\mathrm{Tb}$ was considered those states where the incidence of TB is higher than 16.7 per 100,000 population (by reference to the national incidence of TB in 2009).

Degree of marginalization for municipality of birth was scored according to published by the National Population Council (CONAPO), in count II Population and Housing 2005 National Survey of Occupation and
Employment (ENCE) 2005 (fourth quarter) and consists of a summary measure to differentiate states and municipalities as the overall impact of the deficiencies that affect the population as a result of lack of access to education, residence in inadequate housing, the perception of insufficient monetary income and those related to the residence in small towns.

Host clinical factors considered for the study were: living with tuberculosis patients, contact with chronic coughers, nutritional status, smoking, alcohol, illicit drug use, use of Highly Active Antiretroviral Therapy (HAART), CD4+ cells count and HIV-1 RNA viral load.

Frequencies were obtained; we verified the type of distribution by the Kolmogorov-Smirnov test. Continuous variables were analyzed with getting normal distribution mean and standard deviation and as median and interquartile range for different distribution than normal. In nominal or ordinal qualitative variables frequencies and percentages were obtained using SPSS version 15.0.

Bivariate analysis was performed with chi square test. Odds Ratio (OR) with confidence intervals 95\% was calculated to measure the effect of each risk factor. To adjust for the effects of potential confounders, we used logistic regression models $\mathrm{p} \leq 0.05$ were considered significant, it was calculated using STATA statistical software version 11.1.

\subsection{Ethical}

The study was approved by the Local Committee for Health Research 35021 Hospital de Infectologia "La Raza" National Medical Center, with corporate registration number R-2010-35021-3. Writed informed consent was obtained from all participants for the implementation of PPD.

\section{RESULTS}

The study cohort consisted of $700 \mathrm{HIV}$-infected adult patients aged 16 years or older who were receiving ART between March 1st to 30 June 2011.

Table 1. Description of HIV-Tb cases $(n=47)$

\begin{tabular}{lcc}
\hline Tuberculosis localitation & No. & $(\mathbf{\%})$ \\
\hline Extrapulmonary & 20 & 42.5 \\
Disseminated & 14 & 29.8 \\
Pulmonary & 13 & 27.7 \\
Extrapulmonary TB (Localization) $(\mathbf{n}=\mathbf{2 0}) *$ & \\
Meningeal & 10 & 50.0 \\
Lymph node & 9 & 45.0 \\
Bone & 1 & 5.0 \\
\hline
\end{tabular}

*Extrapulmonary TB cases, HIV: Human Immunodeficiency Virus, Tb: Tuberculosis 
Table 2. Socio-demographic variables

\begin{tabular}{|c|c|c|c|}
\hline Variable & ORp & $\mathrm{CI}_{95 \%}$ & $\mathrm{p}^{*}$ \\
\hline \multicolumn{4}{|l|}{ Schooling } \\
\hline superior education & Ref & - & - \\
\hline Medial superior education & 0.85 & $0.36-2.00$ & 0.712 \\
\hline Basic education & 0.86 & $0.33-2.22$ & 0.766 \\
\hline \multicolumn{4}{|l|}{ Actividad laboral } \\
\hline Managers, professional and administrative activities & Ref & - & - \\
\hline Education workers/art/entertainment/sports and technical & 1.64 & $0.53-5.06$ & 0.392 \\
\hline Artisans and industry workers/employees/trade and services personals & 1.81 & $0.67-4.85$ & 0.24 \\
\hline Heavy and mobile machinery operators/laborers/scrutiny & 2.64 & $0.80-8.70$ & 0.111 \\
\hline Do not work & 2.2 & $0.68-7.13$ & 0.189 \\
\hline \multicolumn{4}{|l|}{ Marital status } \\
\hline Bachelor & Ref & - & - \\
\hline Married & 1.61 & $0.67-3.88$ & 0.283 \\
\hline Widowed/divorced/separated & 4.46 & $0.64-31.03$ & 0.131 \\
\hline \multicolumn{4}{|l|}{ Socioeconomic level } \\
\hline High & Ref & - & - \\
\hline Medium & 1.25 & $0.59-2.65$ & 0.554 \\
\hline Low & 1.28 & $0.40-4.06$ & 0.672 \\
\hline \multicolumn{4}{|l|}{ Tuberculosis Incidence" (State of birth) } \\
\hline Low incidence $(\leq 16.7)$ & Ref & - & - \\
\hline High incidence $(>16.7)$ & 1.67 & $0.62-4.49$ & 0.308 \\
\hline \multicolumn{4}{|l|}{ Marginalization Degree } \\
\hline Low & Ref & - & - \\
\hline Medium/ High & 3.03 & $0.88-10.43$ & 0.078 \\
\hline \multicolumn{4}{|l|}{ Working in nursing homes } \\
\hline No & Ref & - & - \\
\hline Yes & 2 & $0.12-31.97$ & 0.624 \\
\hline
\end{tabular}

ORp: Paired odds ratio, *Chi square test, Ref: Reference, $\mathbb{~}$ Rate of tuberculosis per 100,000 Population

Table 3. Clinical variables

\begin{tabular}{|c|c|c|c|}
\hline Variable & ORp & $\mathrm{CI} 95 \%$ & $\mathrm{p}^{*}$ \\
\hline \multicolumn{4}{|c|}{ Contact with a patient with pulmonary tuberculosis } \\
\hline Negative & Ref & - & - \\
\hline Positive & 1.75 & $0.57-5.42$ & 0.332 \\
\hline \multicolumn{4}{|c|}{ Contact with people with chronic cough } \\
\hline Negative & Ref & - & - \\
\hline Positive & 2.19 & $0.58-8.36$ & 0.249 \\
\hline Body mass index (BMI) & 0.74 & $0.64-0.86$ & $<0.01$ \\
\hline \multicolumn{4}{|l|}{ Body mass indez (BMI) } \\
\hline Low weight & 3.69 & $1.14-11.97$ & 0.03 \\
\hline Normal weight & Ref & - & - \\
\hline Overweight / obesity & 0.28 & $0.09-0.88$ & 0.03 \\
\hline \multicolumn{4}{|c|}{ Antiretroviral treatment (ARVT) } \\
\hline Yes & Ref & - & - \\
\hline No & 3.87 & $1.83-8.19$ & $<0.01$ \\
\hline CD4+ T lymphocytes $\psi \S$ & 0.46 & $0.32-0.65$ & $<0.01$ \\
\hline \multicolumn{4}{|l|}{ CD4+ T lymphocytes } \\
\hline$\leq 199$ cells $/ \mathrm{mm}^{3}$ & 38.64 & $4.03-370.51$ & $<0.01$ \\
\hline$\overline{2} 00-499$ cells $/ \mathrm{mm}^{3}$ & 2.02 & $0.22-18.29$ & 0.53 \\
\hline$>500$ cells $/ \mathrm{mm}^{3}$ & Ref & - & - \\
\hline Viral load (HIV-1) ${ }^{\psi \S}$ & 1.29 & $1.13-1.48$ & $<0.01$ \\
\hline \multicolumn{4}{|l|}{ Viral load (HIV-1) } \\
\hline$<10,000$ copies $/ \mathrm{ml}$ & Ref & - & - \\
\hline $10,000-100,000$ copies $/ \mathrm{ml}$ & 2.09 & $0.48-9.13$ & 0.324 \\
\hline$>100,000$ copies $/ \mathrm{ml}$ & 9.74 & $3.12-30.38$ & $<0.01$ \\
\hline \multicolumn{4}{|l|}{ Viral load (HIV-1) } \\
\hline Undetectable $(<40$ copies $/ \mathrm{ml})$ & Ref & - & - \\
\hline Detectable $(\geq 40$ copies $/ \mathrm{ml})$ & 4.89 & $1.64-14.54$ & $<0.01$ \\
\hline
\end{tabular}

ORp: Paired odds ratio, *Chi square test, Ref: Reference, $\propto$ Media with standard deviation, $\Psi$ Mediana with interquartile range, $\S$ Analysis with elimination of outliers (r Pearson) 
Paz-Ayar Nibardo et al. / American Journal of Infectious Diseases 9 (4): 142-147, 2013

Table 4. Clinical risk factors with largest Association for the occurrence of tuberculosis in HIV patients

\begin{tabular}{llll}
\hline Variable & ORp & $\mathrm{CI}_{95 \%}$ & $\mathrm{p}$ \\
\hline Body mass index (BMI) ${ }^{*}$ & 0.69 & 0.570 .82 & $<0.01$ \\
CD4+* & 0.25 & $0.13-0.47$ & $<0.01$ \\
Viral load $*$ & 1.39 & $1.17-1.67$ & $<0.01$ \\
\hline
\end{tabular}

Conditional logistic regression model, ${ }^{*}$ Continuous variables

Table 5. Association between addictive substances consumption and occurrence of tuberculosis

\begin{tabular}{|c|c|c|c|}
\hline Variable & RORp & $\mathrm{CI}_{95 \%}$ & $\mathrm{p}^{*}$ \\
\hline \multicolumn{4}{|l|}{ Tobacco use } \\
\hline No & Ref & - & - \\
\hline Yes & 1.04 & $0.51-2.13$ & 0.903 \\
\hline \multicolumn{4}{|l|}{ Smoking } \\
\hline Never smoking & Ref & - & - \\
\hline Use to Smoke & 1.39 & $0.65-2.94$ & 0.395 \\
\hline Current smoking & 0.46 & $0.16-1.36$ & 0.162 \\
\hline \multicolumn{4}{|c|}{ Intensity of smoking (cigarettes/day) ( $\mathrm{n}=\mathbf{2 8}$ cases y 55 controls) } \\
\hline Mild smoker $(<5)$ & Ref & - & - \\
\hline Moderate smoker (6-10) & 1 & $0.09-11.03$ & 1 \\
\hline Severe smoker $(\geq 11)$ & 1.26 & $0.25-6.360$ & 0.782 \\
\hline \multicolumn{4}{|c|}{ Alcoholic beverages consumption } \\
\hline No & Ref & - & - \\
\hline Yes & 1.05 & $0.48-2.33$ & 0.894 \\
\hline \multicolumn{4}{|l|}{ Alcoholism } \\
\hline No & Ref & - & - \\
\hline Use to drink & 0.89 & $0.32-2.47$ & 0.831 \\
\hline Current drinker & 1.14 & $0.49-2.67$ & 0.756 \\
\hline \multicolumn{4}{|l|}{ Drug use } \\
\hline No & Ref & - & - \\
\hline Yes & 0.83 & $0.29-2.34$ & 0.732 \\
\hline
\end{tabular}

ORp: Paired odds ratio, ${ }^{*}$ Chi square test, Ref: Reference

A total of 47 of 700 patients $(6.71 \%)$ had active pulmonary or extrapulmonary TB disease. The most frequent location was extrapulmonary with $42.6 \%$ (20 cases), followed by disseminated with the $29.8 \%$ (14 cases) and pulmonary with the $27.7 \%$ (13 cases); of the total of extrapulmonar cases, $50 \%$ were meningeal $(10$ cases), 45\% lymph node TB (9 cases) and 5\% bones and joints (1 case) (Table 1).

TB patients tended to be younger, 26 to 35 years of age $(44.7 \%)$ and higher proportions of male (97.9\%). The type of work (heavy and mobile machinery operators, laborers and security guards), marital status (widowed, divorced or separated) and low socioeconomic level presented ORp $=2.64(95 \% \mathrm{CI}: 0.80$ $8.70) ; \mathrm{ORp}=4.46(95 \% \mathrm{CI}: 0.64-7.13)$ and $\mathrm{ORp}=1.28$ (95\% CI: 0.40-4.06) respectively.

Greater proportions of TB were originated in a high TB incidence States (ORp = 1.67, (95\% CI: 0.62 -4.49 ) and marginalized regions ORp $=3.03$ (95\% CI: 0.88-10.43) (Table 2).
The clinical factors associated with increased risk were: low body mass index $(\mathrm{BMI} \leq 18.49) \mathrm{ORp}=3.69$ (95 CI 1.14-11.97\%); history of contact with a patient with pulmonary tuberculosis ORp $=1.75$, (95\% CI: 0.57 $5.42)$; and contact with people with chronic cough ORp $=2.19$, (95\% CI: 0.58-8.36).

The lacking of ARV-Therapy increased the risk for developing TB almost 4 times ORp $=3.87$, (95\% CI: 1.8-8.19), patients with 200 or lower CD4 counts had an ORp $=38.64,(95 \% \mathrm{CI}: 4.03-370.51)$ and the HIV-1 RNA viral load $>100,000$ copies $/ \mathrm{mL}$ conferred risk of ORp $=9.74,(95 \%$ CI: 3.12-30.38). Detectable viral load $(\leq 40$ copies $/ \mathrm{mL})$ has an ORp $=4.89$, (95\% CI: $1.64-$ 14.54) (Table 3).

In multivariate analysis only lower CD4 count (ORp $=4.0($ CI95\% 2.13-7.69), $\mathrm{p}<0.01)$, detectable viral load $(\mathrm{ORp}=1.39(\mathrm{CI} 95 \%$ 1.17-1.67), $\mathrm{p}>0.01)$ and lower body mass index (ORp $=1.45$ (CI95\% 1.22-1.76). $\mathrm{p}<0.01)$, were related with screening acceptance. Statistical significance was assumed for $p$-values $\leq 0.01$ (Table 4). 


\section{DISCUSSION}

Tuberculosis is a disease caused by M. tuberculosis; there are several factors that are associated with its development and presentation. TB disease can occur at any stage of HIV disease and its manifestations depend largely on the level of immunosuppression.

Prevalence of TB/HIV-coinfected patients was $6.1 \%$ in the institution studied. Maximum patients in our study were in the age group of $26-35$ years $(44.7 \%)$ and majority $(97.9 \%)$ were males. Descriptive analysis showed that TB patients were more likely to be immunosuppressed and live in particular geographical regions like Baja California, Guerrero, Veracruz, Tabasco, Chiapas and Oaxaca, were has $67 \%$ more risk of $\mathrm{Tb}$, less than that reported by (Zhou et al., 2009) in the Asia-Pacific region, where the risk was 3 times more. On the other hand high grades of marginalization have 3 times more risk of developing $\mathrm{Tb}$ in comparison to the low grade.

Our Findings showed that lower CD4 $\left(<200 / \mathrm{mm}^{3}\right)$, lower BMI and detectable viral load had more probability to develop TB confection. The mean CD4 + lymphocyte difference was statistically significant with $p$ value of 0.01 .

BMI could indirectly describe human immunity function, which influence the progress of the disease. In many publications before, TB- HIV patients have BMI significantly lower than TB or HIV alone. Moreover, lower BMI could become strong predictor to HIV patient's mortality. In our results each unit of BIM increased confers $35 \%$ more protection for not developing TB, result consistent with Hanrahan et al., 2010 who noted that overweight and obesity are associated with reduction in the risk of developing TB; they showed that $\mathrm{BMI}<17.0$ represents 3.8 more risk of having $\mathrm{Tb}$.

Most of the subjects (42.6\%) in our study coursed with extrapulmonary TB. While pulmonary $\mathrm{TB}$ is a common presentation in HIV negative cases, it was present in only $27.7 \%$ of HIV-TB coinfected cases in our study. Disseminated TB involving both pulmonary and extrapulmonary sites was also frequent $(29.8 \%)$ in this study population, contrary to what was reported by (Girardi et al., 2012) where 80\% were pulmonary location. On the other hand the 2012 WHO reported similar data, which describes $60 \%$ of extrapulmonary tb in HIV patients.

Schooling was not related as a risk factor to develop TB in our population, contrary to the data of (Miranda et al., 2009), who describes 3 times more risk in developing TB in people with $\leq 3$ years of education.

In relation to employment, patients who work as heavy equipment operators, drivers, workers of construction as pawns and vigilant, although it was not significant, have tendencies almost 3 times more risk as opposed to those who engage in activities managerial or professional. This is something new in our study because the labor activity as a risk factor for $\mathrm{Tb}$ only has been studied worldwide in free HIV health workers and miners (Khayyam et al., 2010).

No association was found between consumption of addictive substances such as alcohol and tobacco, probably due to the small number of patients. There is evidence showed in a study carried out in 2 rural areas China (Wang and Shen, 2009) where smoking was found to be associated in $93 \%$ of the patients with TB disease; as well, a study in the South of India 21, reporting 2 times more risk of TB in alcoholic beverages consumers.(Table 5).

Patients without ART have higher risk (ORp 3.8) to develop TB. Consistent with other studies, (Girardi et al., 2000; Tabarsi et al., 2012) find that using ART, with 2 or 3 drugs, has a protective effect $(\mathrm{RR}=0.16$ and 0.08 respectively) in relation to those who did not use any scheme or used monotherapy.

Tabarsi et al. (2012), showed protection through the use of art $(\mathrm{P}<0.001)$. Another cohort study conducted in Europe and North America 25, in cities with high incidence of $\mathrm{Tb}$ (20 cases per 100,000 population), shows that use of art is a protective factor $(\mathrm{RR}=0.87)$, only when ART start with high CD4 count.

\section{CONCLUSION}

In our study, CD4 + lymphocyte count was found strongly associated with the development of $\mathrm{Tb}$, with counts $<200$ cells $/ \mathrm{mm} 3(\mathrm{ORp}=38.6)$; being higher and consistent with the report by (Antonucci et al., 1995), in a multicenter cohort study in 23 hospitals in Italy, where the risk was almost 5 times higher in patients with less than 200 cells $/ \mathrm{mm}^{3}$. In addition, (Hanrahan et al., 2010), in another cohort study reported 14 times more risk in $\mathrm{HIV}$-infected population.

HIV-1 RNA viral load was found strongly associated with TB development $(\mathrm{ORp}=9.7)$, mainly with $>100,000$ copies $/ \mathrm{mL}$, consistent with the cohort of South Africa held by (Wang and Shen, 2009), who reports a risk of almost 4 times more when de viral load was $>5,000$ copies $/ \mathrm{mL}$.

The strengths of our study are based in the analysis of socio-demographic and clinical risk factors exclusively in infected HIV patients in Mexico. In addition, there are few studies that involve variables such as TB incidence and marginalization degree of as risk factors.

Our study have problems with precision, we obtained wide confidence intervals on variables of interest, mostly because the small sample size. Matching and conditional logistic regression model controlled the validity. So it is a study that has internal validity and therefore we can infer our results could be used in other groups of HIV infected patients. 
These results highlight the need for effective monitoring procedures in AIDS patients and the continuous training of health personnel to ensure data collection, complete and accurate:

- Declaration of conflict of interest

- No conflicts of interest

\section{REFERENCES}

Alvarez-Uria, G., M. Midde, R. Pakam, P.K. Naik, 2013. Diagnostic and prognostic value of serum albumin for tuberculosis in HIV infected patients eligible for antiretroviral therapy: Data from an HIV cohort study in India. Bioimpacts, 3: 123-128. DOI: 10.5681/bi.2013.025

Antonucci, G., E. Girardi, M.C. Raviglione and G. Ippolito, 1995. Risk factors for tuberculosis in HIVinfected Persons. A prospective cohort study. The Gruppo Italiano di Studio Tubercolosi e AIDS (GISTA). JAMA, 274: 143-148. PMID: 7596002

Bautista-Arredondo, S., M.A. Colchero, M. Romero, C.J. Conde-Glz and S.G. Sosa-Rubi, 2013. Is the HIV Epidemic Stable among MSM in Mexico? HIV prevalence and risk behavior results from a nationally representative survey among men who have sex with men. PLoS One, 5: e72616-e72616. DOI: 10.1371/journal.pone.0072616

Blanc, F.X., T. Sok, D. Laureillard, L. Borand and C. Rekacewicz et al., 2011. Earlier versus later start of antiretroviral therapy in HIV-infected adults with tuberculosis. N Engl. J. Med., 365: 1471-1481.

De Luca, M., C. Magis-Rodriguez and E. Bravo-Garcia, 2010. AIDS epidemics in México until 2008. Gac. Méd. Méx., 146: 45-49.

Fox, G.J., S.E. Barry, W.J. Britton and G.B. Marks, 2013. Contact investigation for tuberculosis: A systematic review and meta-analysis. Eur. Respir. J., 41: 14056. DOI: 10.1183/09031936.00070812

Girardi, E., F. Palmieri, C. Angeletti, P. Vanacore and A. Matteelli et al., 2012. Impact of previous ART and of ART initiation on outcome of HIV-associated tuberculosis. Clin. Dev. Immunol. DOI: 10.1155/2012/931325

Girardi, E., G. Antonucci, P. Vanacore, M. Libanore and I. Errante et al., 2000. Impact of combination antiretroviral therapy on the risk of tuberculosis among persons with HIV infection. AIDS, 14: 19851991. PMID: 10997404

Gomes, T., S.A. Vinhas, B. Reis-Santos, M. Palaci and R.L. Peres et al., 2013. Extrapulmonary tuberculosis: Mycobacterium tuberculosis strains and host risk factors in a large urban setting in Brazil. PLoS One, 8: e74517-e74517. DOI: 10.1371/journal.pone.0074517
Hanrahan, C.F., J.E. Golub, L. Mohapi, N. Tshabangu and T. Modisenyane et al., 2010. Body mass index and risk of tuberculosis and death. AIDS, 24: 15011508. DOI: 10.1097/QAD.0b013e32833a2a4a

Kaplan, J.E., C. Benson, K.K. Holmes, J.T. Brooks and Alice Pau et al., 2009. Guidelines for prevention and treatment of opportunistic infections in HIV-infected adults and adolescents. MMWR, 58: 1-198.

Khayyam, K.U., S. Patra, R. Sarin and D. Behera, 2010. Tuberculosis among health care workers in a tertiary care institute for respiratory diseases in New Delhi. Ind. J. Tuberc., 57: 192-198. PMID: 21141337

Kyeyune, R., S. den Boon, A. Cattamanchi, J.L. Davis and W. Worodria et al., 2010. Causes of early mortality in HIV-infected TB suspects in an east African referral hospital. J. Acquir. Immune Defic. Syndr., 55: 446-450. PMID: 21105258

Miranda, A.E., J.E. Golub, F.L. Fde, E.N. Maciel and F.G. Mde et al., 2009. Tuberculosis and AIDS comorbidity in Brazil: Linkage of the tuberculosis and AIDS databases. Braz J. Infect. Dis., 13: 137-141. PMID: 20140359

Sterling, T.R., P.A. Pham and R.E. Chaisson, 2010. HIV infection-related tuberculosis: Clinical manifestations and treatment. Clin. Infect. Dis., 50: S223-S230. DOI: 10.1086/651495

Tabarsi, P., E. Chistsaz, A. Moradi, P. Baghaei and P. Farnia et al., 2012. Treatment outcome, mortality and their predictors among HIV-associated tuberculosis patients. Int. J. STD AIDS, 23: e1-e4. DOI: 10.1258/ijsa.2009.009093

Vazquez-Martinez, J.L., M.G. Mercadillo-Pérez and J.G. Celis-Quintal, 2011. Mortality from the HIV/AIDS in the Instituto Mexicano del Seguro Social. Rev. Med. Inst. Mex. Seguro. Soc., 49: 109-115. PMID: 21513670

Wang, J. and H. Shen, 2009. Review of cigarette smoking and tuberculosis in China: Intervention is needed for smoking cessation among tuberculosis patients. BMC Public Health, 9: 292-292. DOI: 10.1186/1471-2458-9-292

Zenteno-Cuevas, R., E. Montes-Villasenor, J. MoralesRomero, G.C.M. del Campo and B. Cuevas, 2011. Co-infection and risk factors of tuberculosis in a Mexican HIV+ population. Rev. Soc. Bras. Med. Trop., 44: 282-285. PMID: 21901871

Zhou, J., J. Elliott, P.C. Li, P.L. Lim and S. Kiertiburanakul et al., 2009. Risk and prognostic significance of tuberculosis in patients from The TREAT Asia HIV Observational Database. BMC Infect. Dis., 9: 46-46. PMID: 19383122 